\section{Falls Prevention Awareness Day - September 22, 2016}

September 22, 2016, marks the 9th annual observation of Falls Prevention Awareness Day in the United States. Falls are the leading cause of injury, death, and disability for older persons in the United States. ${ }^{*}$ This issue of MMWR includes a report describing the epidemiology of falls among older adults, and how health care providers can use CDC's STEADI (Stopping Elderly Accidents, Deaths, and Injuries) initiative $^{\dagger}$ to reduce preventable falls. STEADI provides tools for health care providers to screen older adult patients, assess fall risk, and provide effective interventions.

In 2011, health department and health system partnerships in Oregon and New York used CDC funding to implement STEADI into their primary care practices (1). Before implementing STEADI, health care providers in these sites rarely talked to their older adult patients about falls $(1,2)$. After implementation, participating health care providers in New York screened and assessed $65 \%$ of older adult patients for fall risk (2), and participating health care providers in Oregon screened and assessed approximately half of all older adult patients ( 1 ).

To help prevent older adult falls, health care providers are encouraged to take three steps: 1) screen patients for fall risk, 2) review and manage patients' medications that might increase fall risk, and 3) recommend daily vitamin D supplements for improved bone, muscle, and nerve health. Additional information is available at http://www.cdc.gov/steadi.

*http://www.cdc.gov/injury/WISQARS.

$\dagger^{\dagger}$ http://www.cdc.gov/steadi.

\section{References}

1. Casey CM, Parker EM, Winkler G, Liu X, Lambert GH, Eckstrom E. Lessons learned from implementing CDC's STEADI falls prevention algorithm in primary care. Gerontologist 2016;gnw074. http:// dx.doi.org/10.1093/geront/gnw074

2. Parker EM, Lee R, Floyd F, et al. Making older adult fall prevention part of routine care in a large health system in New York state. Gerontologist 2015;55(Suppl 2):320.

\section{Falls and Fall Injuries Among Adults Aged $\geq 65$ Years — United States, 2014}

\author{
Gwen Bergen, $\mathrm{PhD}^{1}$; Mark R. Stevens, MA, MSPH${ }^{2}$; \\ Elizabeth R. Burns, $\mathrm{MPH}^{1}$
}

Falls are the leading cause of fatal and nonfatal injuries among adults aged $\geq 65$ years (older adults). During 2014, approximately 27,000 older adults died because of falls; 2.8 million were treated in emergency departments for fallrelated injuries, and approximately 800,000 of these patients were subsequently hospitalized.* To estimate the numbers, percentages, and rates of falls and fall injuries among older adults by selected characteristics and state, CDC analyzed data from the 2014 Behavioral Risk Factor Surveillance System (BRFSS) survey. In 2014, 28.7\% of older adults reported falling; the estimated 29.0 million falls resulted in 7.0 million injuries. Known effective strategies for reducing the number

$\overline{{ }^{*} \text { http://www.cdc.gov/injury/wisqars. }}$

\section{INSIDE}

999 HIV Testing Experience Before HIV Diagnosis Among Men Who Have Sex with Men -

21 Jurisdictions, United States, 2007-2013

1004 Unmet Needs for Ancillary Services Among Men Who Have Sex with Men and Who Are Receiving HIV Medical Care — United States, 2013-2014

1008 Update: Influenza Activity — United States and Worldwide, May 22-September 10, 2016

1015 Notes from the Field: Furanyl-Fentanyl Overdose Events Caused by Smoking Contaminated Crack Cocaine - British Columbia, Canada, July 15-18, 2016

1017 Notes from the Field: Pediatric Death from Meningococcal Disease in a Family of Romani Travelers - Sarasota, Florida, 2015

1019 QuickStats

Continuing Education examination available at http://www.cdc.gov/mmwr/cme/conted_info.html\#weekly.

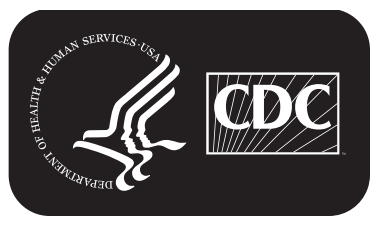

U.S. Department of Health and Human Services Centers for Disease Control and Prevention 